\title{
THE MEDIATION EFFECT OF HEALTH BEHAVIOR ON THE RELATIONSHIP BETWEEN MATERNAL DEPRESSION AND MATERNAL-FETAL ATTACHMENT
}

\author{
Rufidah Maulina, Su-Chen Kuo, Chieh Yu Liu, Yu-Ying Lu \\ National Taipei University of Nursing and Health Sciences
}

\begin{abstract}
Background: Numerous studies have shown the adverse effects of maternal depression, which impacts both mother and child as well as can lower the maternal-fetal attachment. However, during pregnancy, a pregnant woman tends to practice healthier behavior to improve her health and the baby. A gap remains in our understanding of the effect of health behavior as the variable which influences the relationship between depression and maternal-fetal attachment. This study aimed to investigate the mediating effect of healthy behavior on the relationship between maternal depression and maternal-fetal attachment.

Subjects and Method: A cross sectional study was conducted at Community Health Centers in Surakarta, from July to September 2019. A sample of 224 pregnant women was selected for this study. The dependent variable was a healthy lifestyle. The independent variable was depression and maternal-fetal attachment. Depression was measured by Edinburgh Postpartum Depression Scale (EPDS). The data were analyzed by Hayes' process mediation analysis.

Results: Health-promoting lifestyle totally mediated the relationship between maternal depression and maternal-fetal attachment $(b=-0.25 ; \mathrm{SE}=0.10 ; 95 \% \mathrm{CI}=-0.47$ to 0.05$)$.

Conclusion: Health-promoting lifestyle and behavior mediates the relationship between maternal depression and maternal-fetal attachment.

Keywords: Nursing, midwife, maternal-fetal attachment, prenatal depression, healthpromoting lifestyle

\section{Correspondence:}

Rufidah Maulina. National Taipei University of Nursing and Health Sciences. Taipei, Taiwan. Email: rufidahmaulina@gmail.com. Mobile: +6282221525673.
\end{abstract}

